\title{
Abordagem etnográfica com crianças no contexto da instituição de educação infantil: uma aventura antropológica
}

The ethnographic approach with children in the contexto of the Instituto de Educação Ivoti: an anthropological adventure

\author{
Raquel Dilly Konrath* \\ raqueldilly@terra.com.br
}

Resumo: Sustenta-se hoje a necessidade de revermos a nossa postura investigativa sobre as crianças, rompendo com os paradigmas que as compreendem como sujeitos passivos, reprodutoras ou receptoras de cultura. Na concepção da sociologia da infância, essa visão é reformulada, concebendo as crianças como participantes ativos da construção social. Nessa visão, compreende-se a infância como categoria social e cultural e as crianças como importantes referentes empíricos de estudo. Isso significa que é preciso estudá-las a partir de si próprias. Nesse sentido, a abordagem etnográfica apresenta-se como um desafio e uma grande possibilidade de conduzir as pesquisas organizacionais investigativas com crianças. A etnografia nos permite estudar a criança como "Outro", como uma Alteridade, mas justamente para conhecê-la como "Outro" a partir de uma convivência prolongada e da participação de suas rotinas na Instituição de Educação Infantil, grupo social a ser pesquisado. A opção pela abordagem etnográfica consiste em atender às singularidades da realidade social e cultural de uma turma de crianças em uma Instituição de Educação Infantil da Encosta da Serra/RS para procurar compreender os valores éticos e morais, os códigos, as intenções e motivações que orientam a seleção, a significação e a utilização dos brinquedos na rotina da escola e de que forma eles podem ser constitutivos das culturas infantis. Através da análise desses resultados, pretende-se contribuir com os estudos sobre a Educação Infantil e suas práticas pedagógicas, trazendo reflexões sobre a construção de uma postura pedagógica que tenha como pressuposto a escuta e olhar atento "com" e não "sobre" as crianças, reconhecendo-as em suas diferentes manifestações culturais.

Palavras-chave: pesquisa, etnografia, crianças

Abstract: Nowadays it is supported the need to review our investigative attitude towards kids, breaking with the paradigms which understand them as passive subjects, reproducing or receiving culture. In the conception of the childhood sociology, this view is reformulated by conceiving kids as active participants into the social construction. According to this point of view, childhood is understood as a social and cultural category and children are viewed as important empirical study references. It means that it is important to study them based on themselves. So, the ethnographic approach is presented as a challenge as well as a great possibility to guide investigative organizational researches with kids. Ethnography allows us to study a child as "another one", like one alterity, but to know him as "another one" from a long interaction and from participating in his routines during the Primary School Institution, which is the social group that is being investigated. The option for the ethnographic approach aims at attending the singularities of the cultural and social reality of a kids' class in one Primary School Institution in Encosta da Serra/ $R S$, in order to understand the ethical and moral values, the codes, the intentions and motivations that orientate the selection, the meaning and the usage of toys in the school routine, as well as the ways they may be constitutive of childhood cultures. Through an analysis of such results, it is intended to contribute with the current studies about Primary School and its pedagogical praxis, raising up reflections upon the construction of a pedagogical attitude that supposes listening and looking closely "at" children and not "about" the children, recognizing them through their different cultural manifestations.

Keywords: research, ethnography, children

*Professora no Instituto Superior de Educação Ivoti/ISEI e Doutoranda em Processos e Manifestações Culturais pela Feevale/NH. 


\section{Introdução}

A criança não sabe senão viver a sua infância. Conhecê-la pertence ao adulto. Mas o que vai prevalecer neste conhecimento: o ponto de vista do adulto ou da criança? (WALLON, 1989, p. 9).

Como olhamos e vemos as crianças? Quem são e como são as crianças que vivem hoje nas Instituições de Educação Infantil? De que maneira vivem a sua infância? Como participam da construção de um mundo social? Os brinquedos são constitutivos das culturas infantis? Por quê? Como entender a mensagem dos brinquedos? Que valores éticos e morais, códigos, intenções e motivações orientam sua seleção, significação e utilização? Como decifrar as estratégias utilizadas pelas crianças para lidar com esses artefatos culturais? Como e quais relações sociais entre crianças e adultos são marcadas pelo brinquedo? Que implicações os brinquedos, como elementos constitutivos de culturas infantis e as próprias produções culturais das crianças, trazem para a prática pedagógica da escola e de seus professores? Essas são apenas algumas de muitas outras perguntas e inquietações que servirão como eixo articulador da pesquisa com uma turma de crianças num contexto social de uma Instituição pública de Educação Infantil em um município da Encosta da Serra/RS, ao desafio de se lançar por uma aventura da antropologia: a abordagem etnográfica.

A abordagem etnográfica sustenta a ideia de que para investigar as crianças de um contexto, organização ou instituição é preciso estudá-las a partir de si próprias e não de generalizações, modelos universalizantes ou padrões sociais dos adultos. Nessa abordagem, reformula-se a postura investigativa com as crianças e perspectiva-se a visão em torno delas como importantes atores sociais e como produtoras e (re)-construtoras de cultura, e não meras reprodutoras, rompendo com alguns paradigmas teóricos existentes. Nessa perspectiva, também desconstrói-se a concepção de condicionamento passivo das crianças, e passa-se a concebê-las como participantes ativos da construção de sua própria realidade cultural e social, dando-as voz, vez e possibilidade de se expressarem de forma autônoma e espontânea, manifestando, assim, a sua própria forma de ser criança e de ver o mundo.

Assim sendo, torna-se imprescindível em um primeiro momento, buscar compreender alguns requisitos e fundamentos teóricos que conduzem e ancoram a pesquisa e os estudos a partir de uma perspectiva etnográfica, justificando a escolha dessa abordagem para a investigação no contexto da Educação Infantil.

\section{Por um olhar e uma escuta atenta com as crianças e a infância}

\begin{abstract}
Sustenta-se a necessidade de se rever as posturas das investigações sobre as crianças como atores, propondo-se um olhar que as considere como sujeitos empíricos, com voz, vez e expressões próprias. Por esse enfoque, é possivel ver as crianças a partir de suas experiências e manifestações, principalmente aquelas construidas por meio das relações estabelecidas com seus pares e não mais como sujeitos passivos, ainda que elas sejam interdependentes dos adultos ou de outros grupos sociais, como, por exemplo, a família, os contextos institucionais de educação e o Estado. (MARTINS FILHO, 2015, p. 9).
\end{abstract}

Os estudos sobre as crianças a partir de si próprias ainda são recentes. Eles resultam de teorias e pesquisas de diferentes áreas, mas em que todas se remetem à compreensão de que as crianças são participantes ativas na constituição de diferentes contextos socioculturais, assim como, também por esses, são constituídas e influenciadas. No sentido aqui apresentado isso resulta dos estudos da sociologia e antropologia, mas isso não significa que não sejam possíveis outras interpretações. Reconhece-se, a partir das explicações dessas áreas, que as crianças devem ser vistas e ouvidas como 
“sujeitos pertencentes e produtores de lugares e culturas, não só nas pesquisas [...], como na vida" (VASCONCELLOS, 2007, p. 9). Assim, suas diferentes manifestações e expressões são valorizadas e reconhecidas em interação com os outros sociais.

Seguindo por esse viés, compreendemos que a criança "não existe no singular, sendo mais apropriado falarmos em crianças, que juntas em sua pluralidade, formam a categoria infância." (MARTINS FILHO, 2015 , p. 7). E ao considerarmos a variedade de contextos sócio culturais e as diferentes vivências das crianças, assim como ao reconhecermos e valorizarmos as suas expressões, também não podemos mais "falar numa infância, mas em infâncias que são múltiplas e plurais nas suas mais diversas formas de manifestações e produções culturais.” (MARTINS FILHO, 2015, p. 10).

Desse modo, sustenta-se uma nova forma investigativa, não mais "sobre" as crianças, na visão do adulto, mas "com elas", reconhecendo-as como importantes referentes empíricos no estudo da infância. Ao pesquisá -la e estudá-la, coloca-se a criança no centro da indagação, estudando-a partir de si própria. Isso significa procurar e aprender a ouví-la e olhá-la em seu contexto e em seus códigos de valores e sentidos.

Considerando essas mudanças de olhar e ver a infância e a criança, Cohn (2009), nos provoca a olhar para a infância e a criança de forma muito particular, pois suas vivências e experiências são diferentes em cada lugar e, assim, teríamos que entendê-las em seu próprio contexto sociocultural. De acordo com a autora, os conceitos de criança e de infância nos parecem muito naturais, mas nos escondem inúmeras complexidades, uma vez que diferentes culturas lidam de forma diferente com suas crianças. Isso nos leva a inúmeros outros questionamentos e interrogações, os quais num primeiro momento possam até nos parecer inquestionáveis, uma vez que naturalizarmos nossos discursos e enxergarmos os fatos e situações a partir dos nossos valores e crenças. É comum ainda reduzirmos as peculiaridades e individualidades das crianças, bem como suas fantasias e o seu imaginário infantil à nossa visão, construída a partir das nossas concepções, ideais e crenças, como também das nossas próprias aspirações. Temos dificuldade para compreender na prática que a criança é um outro indivíduo, que tem a sua forma peculiar de ver e olhar para o mundo. Olhamos para a criança com a nossa lente já viciada com conceitos préconcebidos que se transformam em preconceitos e acostumam os nossos olhos a enxergarmos a infância sob o nosso prisma, desconsiderando, muitas vezes, suas potencialidades e necessidades.

Como adultos, queremos que a criança enxergue o mundo, não com um olhar livre e aberto, mas que ela olhe através da nossa lente, da nossa visão construída e já condicionada e viciada pelos nossos próprios desejos, valores, frustrações e neuroses, pelas nossas experiências vividas. Dessa forma, agimos como se a criança fosse uma extensão nossa, dos nossos projetos de vida e não como se nós fôssemos a extensão da criança que um dia já fomos. Temos a pretensão de educar, modificar e transformar as crianças, através de projetos pessoais e currículos educacionais, o nosso modo de ver e interpretar o mundo, desconsiderando, muitas vezes, a sua forma própria de o sentir e perceber, construindo seus próprios sentidos e significados. Controlamos seu tempo, o seu espaço e as suas ações definindo e escolhendo por ela o que fazer, como fazer e ainda antecipamos, segundo a nossa visão, o porquê fazer, com o intuito de produzir uma criança idealizada e desejada.

A criança é um ser que dá sentido ao mundo em que vive fazendo diferentes leituras das tramas sociais. Tem, portanto, no decorrer da vida, não só a possibilidade de aprender como também de contribuir para a constituição de um outro 
momento histórico. (MÜLLER; REDIN, 2007, p. 17).

Ao olharmos para a criança dessa forma, talvez tenhamos que mudar o nosso foco, nos libertarmos dessa forma unilateral de olhar e vê-la, para enxergarmos novas possibilidades de percepção sobre a criança.

Abrir espaços para seus movimentos, permitir sua expressão, estimular seus desejos, curiosidades dialogar honesta e abertamente com ela, reconhecer sua presença, seus sonhos, sua voz e ajuda-la a descobrir as coisas por seus próprios meios e ritmos. Sem violencia, mas com lucidez e clareza. Permitindo que ela construa seus mundos tantos quantos forem necessários. Com tevê, bichos, microcomputadores, duendes ou darks, poemas e guache, música e números, com humor e amor, com trabalho e tesão. (DAMAZIO, 1994, p. 38).

Para tanto, é imprescindível ouvir a criança, olhar com a criança e não somente falar e olhar para ela com um olhar adultocêntrico. Nobre (2007, p. 58) nos provoca ao trazer que pouco nos perguntamos ou nos indagamos: "O que a criança tem a dizer sobre si mesma? Como elas entendem o mundo e o seu lugar nele?" Para falar e olhar com a criança também se faz necessário:

[...] compreender os modos de vida próprios das crianças em diferentes culturas, além da curiosidade em decifrar as estratégias utilizadas por elas para lidar com um mundo próprio das crianças, sem desconectá-lo do mundo dos adultos. (VASCONCELLOS, 2007, p. 8).

Considerar e compreender o mundo próprio da criança nos faz rever a ideia de que a cultura é simplesmente e ingenuamente transmitida através de diferentes artefatos, como: objetos, informações, crenças ou valores, mas que ela mesma é capaz de formular sentidos ao mundo que a rodeia. Ao considerar também o olhar da criança como uma importante possibilidade de produzir, construir e narrar as histórias sobre a infância, reco- nhecemos que existe uma variedade infindável de possibilidades de se olhar para as histórias produzidas e narradas sobre a infância e criança. Além disso, não é mais concebível e possível reconhecer essas histórias como legítimas, sem ouvir e considerar o olhar de uma das partes que também as compõem, ou seja, a própria criança.

Ainda temos certa dificuldade de assim compreendê-la e enxergá-la, mas parece-nos uma importante possibilidade de repensarmos nossa forma de olhar e ler o mundo. Quem sabe, se ao menos reconhecermos com legitimidade e respeito as diferenças existentes em nossa sociedade encontraremos novos sentidos frente aos impasses tão complexos colocados na atualidade.

\section{Etnografia com crianças no contexto da instituição de educação infantil}

\section{[...] compreendemos que não consegui- mos ser inteiramente fidedignos ao que elas pensam e dizem sobre o mundo, pois temos limites como intérpretes e traduto- res desses pontos de vista na comunidade acadêmica. (DELGADO, 2007, p. 111- 112).}

Ao explicitar, nesse contexto, a compreensão de crianças e de infâncias, sustenta-se também a necessidade de identificá-las e diferenciá-las na sua forma de constituição. Sendo assim, reforça-se a compreensão nesse contexto, referindo-nos à infância como categoria social e cultural, constituída e construída nas mais diversas formas de manifestações e produções culturais. Essas crianças se constituem na singularidade e na pluralidade, ou seja, se identificam e se diferenciam em suas variadas vivências e contextos socioculturais, e que, por essa razão, formam essas diferentes categorias de infância, evitando assim enxergá-las e enquadrá-las a partir de generalizações e padronizações.

No contexto da pesquisa, as crianças serão investigadas junto a seus pares, entendidos aqui como grupo 
que partilha o mesmo espaço físico numa rotina habitual, e que umas com as outras, estabelecem relações sociais e culturais. As culturas de pares podem ser definidas, segundo Martins Filho (2015, p. 26), “como um conjunto de atividades ou rotinas, artefatos, valores e preocupações que as crianças produzem e partilham na relação com os seus pares, sejam originados do mundo adulto ou criados e transformados no próprio grupo de crianças".

Ao se buscar compreender e decifrar as estratégias utilizadas pelas crianças de uma turma no contexto de uma Instituição de Educação Infantil para lidar com os brinquedos como elementos constitutivos de culturas infantis e as próprias produções culturais, é importante situar o universo simbólico expresso nas suas brincadeiras. Isso aponta para as diferenças de significado e interpretações que podemos obter em se tratando de contexto sócio cultural específico, num dado momento histórico e temporal. Captar, portanto, os significados das crianças traduzidas e refletidas em suas manifestações culturais a partir dos brinquedos, nos aponta para muitas reflexões e incertezas. Implica em interpretar suas opiniões e seus pontos de vista, que segundo Delgado (2007, p.110) nos traz limites, pois a ludicidade, o imaginário e o simbólico que constituem as culturas das crianças que se manifestam ao estabelecerem e vivenciarem diferentes relações entre elas e os adultos, impedem uma "tradução fidedigna dos seus pontos de vista e opiniões, pois entendemos que jamais conseguiremos captar inteiramente a riqueza e a versatilidade das suas respostas e criações".

Segundo Barthes (2013), o poder exercido pela linguagem, seja verbal ou não verbal, tem como utopia diminuir as diferenças entre os sujeitos, para constituir a ideia do "viver junto". No entanto, argumenta que "de qualquer maneira, não existem máquinas de ler, de escutar os sentidos.” (BARTHES, 2013, p.289). Isso sig- nifica que mesmo participando das manifestações e expressões culturais, através de uma escuta e um olhar atento, essas ainda podem ser intuitivas e subjetivas, pois serão interpretadas e explicadas a partir da nossa construção e produção de significados, e que podem não representar o mesmo sentido de quem as produz: as próprias crianças. Para isso, precisamos desafiar as suposições:

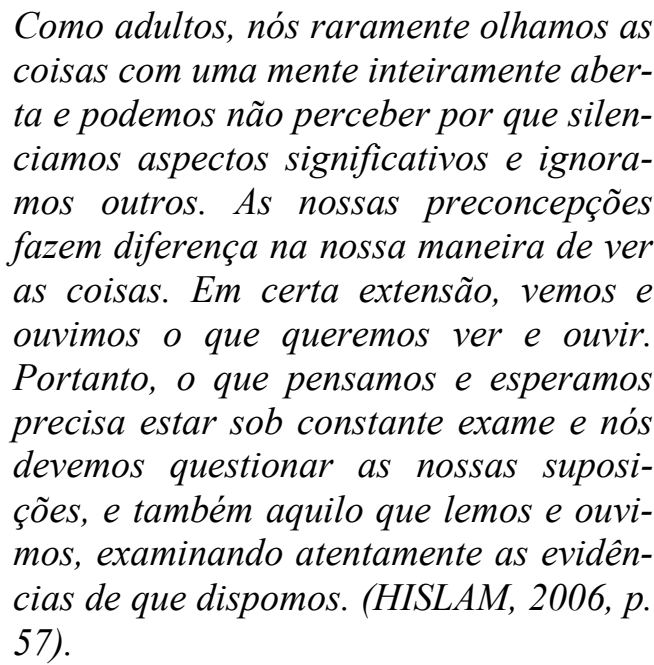

Mesmo que a escuta se faça a partir de interpretações subjetivas e intuitivas, ainda pode ser um importante caminho para respeitarmos as individualidades e as diferentes manifestações culturais, não procurando homogeneizar, através de rituais e padrões de comportamento, as atitudes das crianças.

Por se tratar de significados produzidos e compartilhados num contexto coletivo, ou seja, por uma turma, mas que se compõe de individualidades, de diferentes crianças e contextos, também é necessário assinalar os desafios que se apresentam, pois, "produzir e compartilhar significados não é algo tranquilo. Isto acontece em meio a conflitos de interesses entre adultos, jovens e crianças que estão sempre em busca de hegemonia para seus significados.” (DELGADO, 2007, p. 110). Nesse sentido, faz-se necessário buscar metodologias adequadas para investigar crianças num contexto coletivo, definindo e redefinindo, ao longo da trajetória, instrumen- 
tos que possam auxiliar na escuta e no olhar atento sobre as suas vozes e seus pontos de vista.

Ainda, "nas pesquisas com crianças, a ética assume um papel preponderante, uma vez que diferenças de poder entre adultos e crianças podem assumir proporções muito desiguais.” (DELAGADO, 2007, p. 112). Por isso, faz-se necessário também negociar todo o processo da pesquisa com as crianças, não somente com os adultos. As crianças também têm o direito de saber as intenções, e o modo de sua participação na pesquisa, bem como o de escolher em relação à sua participação ou não. Assim, a participação das crianças nos traz diferentes possibilidades e desafios, visto que:

Entendemos que oportunizar a participação das crianças nas pesquisas é algo viável, e que requer um trabalho de nós adultos pesquisadores sobre nossas certezas e convicções. Isso também exige algumas rupturas com os atrofiamentos da fantasia, da afetividade e da sensibilidade. (DELGADO, 2007, p. 124).

Significa abrirmos mão de nossas verdades, de nossos próprios discursos, muitas vezes, massificados e naturalizados, e nos deixar levar pelo olhar e pelas vozes das crianças, abrindo, assim, novas possibilidades para aprender e ensinar em contextos escolares.

\section{Mas, afinal, o que é etnografia?}

A ruptura com o senso comum sem dúvida é hoje uma questão que provoca verdadeira vertigem entre os cientistas sociais de pensarmos que neste "senso comum" estão as suas próprias produções teóricas e conceituais. (ECKERT; ROCHA, 2008, p. 28).

A pesquisa etnográfica tem suas origens na Antropologia, mas hoje já é encontrada em outros campos do conhecimento humano. Ela consiste em um modo de desenvolver novas abordagens de pesquisa em organizações em relação à métodos tradicionais, detectando perspectivas e interpretações divergentes ou diferentes para um mesmo fenômeno. Na história oficial da antropologia ela surgiu como modelo de coleta de dados culturais.

O nascimento da etnografia enquanto método científico, segundo Jaime Júnior (2003, p. 437), “se dá apenas na primeira metade do século XX”. De acordo com o autor, "o surgimento nos trabalhos de campo foram realizados pelo antropólogo norte-americano Franz Boas e, especialmente, pelo polonês naturalizado britânico Bronislaw Malinowski. As duas expedições de Malinowski nas Ilhas Trobiand, nordeste de Nova Guné (De 1915-1916 e 1917-1918), constituíram o "marco de origem da etnografia científica" (JAIME JÚNIOR,2003, p. 437). Argumenta que:

\begin{abstract}
Esse evento representou uma espécie de revolução científica na antropologia, na medida em que redefiniu as crenças, os compromissos básicos dos membros dessa comunidade cientifica a respeito da natureza do conhecimento antropológico. Não seria mais possível acender ao conhecimento de outras sociedades, outras culturas, a partir dos dados fornecidos por viajantes, missionários e funcionários do governo colonial. Somente um olhar disciplinado, isto é, um olhar que apreende a realidade dentro do esquema conceitual fornecido pela teoria antropológica poderia levantar os dados etnográficos, necessários à compreensão do outro.
\end{abstract}

No entanto, no âmbito da teoria e história da antropologia, muitos foram os debates e as divergências em relação a sua conceituação ${ }^{1}$. Alguns estudiosos definiram-na a partir da etimologia da palavra: Etno $=$ cultura e grafia $=$ escrita, e outros a partir de sua prática. Apesar dos muitos e contínuos debates em relação

\footnotetext{
${ }^{1}$ Descrever as divergências no âmbito da teoria e história ao longo dos anos não é objetivo desse texto, mas sugiro nas referências bibliográficas alguns textos de aprofundamento para essas questões.
} 
ao seu método científico desde a sua origem, a etnografia tem sido ainda objeto de intensa problematização, enfocada de acordo com os apontamentos de Jaime Júnior (2003, p. 443), a partir de "dois eixos centrais: a) a relação observador-observado; b) as estratégias narrativas adotadas na escrita do texto etnográfico. Tais discussões se justificam pelo fato da metodologia utilizada e empregada pela etnografia incorporar a subjetividade do pesquisador no processo de produção do conhecimento.

No entanto, tais debates e divergências não devem ser obstáculos para que pesquisadores se lancem a esse desafio investigativo, desde que se levem em conta devidos rigores, necessários na escolha de qualquer outro método científico ou abordagem investigativa. Nesse sentido, algumas ações podem ser sugeridas e alguns passos importantes podem ser seguidos, não como prescrições, mas importantes reflexões.

\section{Os caminhos da etnografia}

Trata-se de pensar a etnografia como o relato de uma experiência conflituosa de um observador, condição para o entendimento do que foi observado. (SILVA, 2009, p. 171).

Apresentou-se a etnografia como uma abordagem investigativa que depende muito da postura metodológica do pesquisador, mas que não a coloca em questão em relação à condução de pesquisas a partir de um estudo etnográfico, buscando a partir dela, compreender as diferenças que resistem a "um mundo cada vez mais homogêneo, refletindo, também, sobre a nossa própria posição nesse mundo e sobre as condições em que buscamos construir a compreensão de alteridade.

Jaime Junior (2003, p. 451-453), apresenta algumas sugestões sobre as quais todo o projeto de pesquisa etnográfica deve estar atento, não como prescrições a seguir, mas como importantes reflexões a fazer. Aponta como primeiro tópico: “A etnografia é construída dentro da tensão entre familiaridade estranhamento". Isso significa que é necessário participar do grupo cultural pesquisado do modo que se consiga transmitir cumplicidade e confiança para procurar compreender os códigos e os significados do grupo pesquisado, mas ao mesmo tempo, conseguir se indagar sobre como aquela realidade social é construída. Essa postura, ou sentimento como é denominado por Da Matta (1978), faz parte, pois sustenta-se num contínuo "de estar lá e do estar aqui como parte das tristezas de um(a) antropólogo(a), um eterno desgarrado de sua própria cultura, mas na eterna busca do seu encontro com outras culturas". E, por isso, a importância do segundo tópico: "A familiaridade requerida para a compreensão do ponto de vista dos atores não deve levar o pesquisador à ilusão de tornar-se nativo". Essa postura é fundamental para o etnógrafo, uma vez que está na posição de aprender a viver com o grupo e não como o grupo pesquisado. O terceiro tópico ajuda na compreensão dessa ideia:

Se o etnógrafo e o nativo são sujeitos que falam a partir de lugares diferentes, $e$ tendo em vista a busca de uma situação menos assimétrica na relação observador-observado, devemos pensar o trabalho de campo como um encontro etnográfico entre o pesquisador e os seus interlocutores. (JAIME JUNIOR, 2003, p. 453).

Nesse aspecto, considera-se o diálogo como postura de trabalho, assumida no estabelecimento das relações entre o pesquisador e o grupo pesquisado. O quarto tópico reforça essa necessidade: “Através do diálogo o etnógrafo poderá construir uma interpretação das práticas significantes dos atores". E ainda complementado pelo quinto tópico: "O diálogo que caracteriza a etnografia começa desde a inserção no campo".

Ainda no que se refere à relação observador-observado, vale lembrar que, no caso da pesquisa em organizações, tal 
como parece configurar-se no campo da etnografia da ciência, essa relação assume contornos particulares, neutralizando o lugar clássico do etnógrafo, uma vez que esse não é, a priori, originário de uma classe, de uma etnia ou de uma nacionalidade tida como superior ou dominante, apresentando-se em linhas gerais, como um igual. (Sexto tópico). (JAIME JUNIOR, 2003, p. 453).

Essa relação exige, tanto do observador e do observado, atitudes de respeito às diferentes culturas, estabelecidas numa relação de confiança e diálogo constante. No entanto, apresenta-se a necessidade do sétimo tópico: "Não existe etnografia sem o diálogo com um referencial teórico". A partir desse aspecto, evidenciamos que a partir da etnografia não estudamos diferentes grupos, mas as situações, ou seja, os fenômenos a partir de diferentes organizações, ou seja, "esta busca de conhecimento é sempre orientada por questões conceituais aprendidas no estudo das teorias socais." (ECKERTH; ROCHA, 2008, p. 12). No entanto, "É importante situar o locus etnografado no sistema econômico e político" (oitavo tópico). Vale ressaltar, nesse aspecto, a importância do contexto da pesquisa, assim como "É imprescindível também proceder à construção histórica do presente etnográfico" (Nono tópico). Essa reconstrução se torna importante, uma vez que o presente observado e presenciado é fruto de uma construção histórica, produzida muito antes da chegada do pesquisador.

Como décimo tópico, o autor levanta a necessidade da pesquisa, para além da ação: "Deve se ter em mente que a etnografia envolve não apenas a prática do trabalho de campo, mas também da passagem do campo ao texto". Esse ato requer do pesquisador muita sensibilidade ao trazer as diferentes interpretações, traduzindo em palavras todas as observações e vivências. E como último tópico, um importante contraponto: "para quem as interpretações dos etnógrafos não são necessariamente validadas ou invalidadas pelo fato ou não de coincidirem ou não, com as interpretações ordinárias, nativas". Quer dizer que, mesmo no caso da rejeição das interpretações do grupo pesquisado, a pesquisa tem o seu valor científico, tomando como mais um dado importante de reflexão, interpretação e pesquisa, a contradição de visões e concepções.

Além da importância de todos os tópicos acima destacados, a abordagem etnográfica exige uma metodologia específica, com técnicas de observação direta e entrevistas que podem se transformar em conversas formais e informais, e que se constituem no "exercício de olhar (ver) e do escutar (ouvir)." (ECKERT; ROCHA, 2008, p.11). O método investigativo etnográfico assim é:

\begin{abstract}
Composto de técnicas e de procedimentos de coleta de dados associados a uma prática de trabalho de campo a partir de uma convivência mais ou menos prolongada do(a) pesquisador(a) junto ao grupo social a ser estudado. (ECKERT; ROCHA, 2008, p. 11).
\end{abstract}

Ao recorrer primordialmente a observação direta como técnica de pesquisa, evidencia-se a importância do(a) pesquisador(a) como peça chave para que o estudo cumpra e garanta o seu rigor metodológico científico, necessário para a sua validação. Por isso, torna-se fundamental ao pesquisador(a) enquanto etnógrafo(a) desenvolver algumas habilidades relacionadas ao ato de situar-se no contexto pesquisado, observar, andar, ver, ouvir e escrever. Trata-se, portanto, de pensar tais habilidades como condição para o entendimento do que foi pesquisado. Ressalta-se como fundamental sua aproximação ao grupo ou instituição a ser estudada "para conquistar a concordância de sua presença para a observação sistemática das práticas sociais" (ECKERTH; ROCHA, 2008, p. 10). E para isso, é imprescindível que o pesquisador (a) compreenda que: "A prática da etnografia se baseia nesta disponibilidade de pesquisar a partir de um método que o(a) coloque no 
encontro direto com os indivíduos e/ou grupos em situações de vida ordinárias." (ECKERTH; ROCHA, 2008, p. 20).

Compreender que a prática etnográfica se baseia na disponibilidade do encontro significa que a aceitação do(a) pesquisador(a) depende, conforme Foote-Whyte (1980), muito mais das relações pessoais que se estabelecessem e se desenvolvem no e com o grupo do das explicações que se pudesse dar. Isto é, a importância crucial de obter apoio dos indivíduos do grupo ou instituição estudada.

Além das técnicas da entrevista e da observação participante, na qual o(a) pesquisador(a) participa sistematicamente da vida social da instituição ou grupo pesquisado, existe outra de extrema importância, que é a técnica da escrita do diário de campo:

Após cada mergulho ao trabalho de campo, retornando ao seu cotidiano de antropólogo, o etnógrafo necessita proceder a escrita de seus diários de campo. [...] Trata-se de anotações diárias do que o(a) antropólogo(a) vê e ouve entre as pessoas com que compartilha um certo tempo de suas vidas cotidianas. [...] Ele é um espaço fundamental para o(a) antropólogo(a) arranjar o encadeamento de suas ações futuras em campo, dúvidas conceituais e de procedimento ético. (ECKERTH; ROCHA, 2008, p. 23).

O caderno de campo como instrumentos de registro, traz todas as situações, fatos e acontecimentos vividos e compartilhados entre o pesquisador(a) e o grupo pesquisado, porém não é algo que possa ser escrito ao mesmo tempo em que o encontro acontece. Seus registros são baseados em outro instrumento que é o caderno de notas. Esse, portanto, é um espaço para registrar “dados, gráficos, anotações que resultam do convívio participante e da observação atenta do universo social onde está inserido e que pretende investigar". Ambos são instrumentos de "transposição de relatos orais e falas obtidos desde a inserção direta do(a) pesquisador(a) no interior da vida social por ele ou por ela observada." (ECKERTH; ROCHA, 2008, p. 23).

Pode-se a esses dois instrumentos agregar ainda o uso de recursos audiovisuais, permitindo ao pesquisador(a) outras e diferentes possibilidades investigativas. Em todos os métodos e instrumentos utilizados na pesquisa etnográfica, exige-se do etnógrafo como pesquisador "tempo, movimento, dinâmica, sequência, sintagma, remetendo-o a uma tripla e inextricável atividade, "sua circulação no campo, sua observação do campo e sua versão do que aconteceu ali e seus significados." (SILVA, 2009, p. 185). Consiste em dizer que:

\section{[...] o oficio do etnógrafo pela observa- ção participante, pela entrevista não- diretiva, pelo diário de campo, pela téc- nica da descrição etnográfica, entre ou- tros, coloca o(a) cientista social, o(a) antropólogo(a), mediante o compromisso de ampliar as possibilidades de reconhe- cimento das diversas formas de partici- pação e construção de vida social. (ECKERT; ROCHA, 2008, p. 29).}

E ao assumir o ofício e o compromisso de participação e construção social, o etnógrafo(a) como pesquisador(a) contribui também para que outras e novas reflexões e estudos acerca das diferenças culturais e sociedades humanas possam acontecer.

\section{Considerações finais: novos olhares, novas possibilidades!!}

Se um homem embarca em uma expedição decidido a provar certas hipóteses e se mostra incapaz de modificar sem cessar seus pontos de vista e de abandonálas em razão de testemunhos, inútil de dizer que seu trabalho não terá valor nenhum. (MALINOWSKI, 1976, p. 65).

Conceber a etnografia como possibilidade e capacidade de modificar olhares e pontos de vista, significa compreendê-la como uma forma de olhar para o mesmo fenômeno sob diferentes e novas perspectivas. E, através dessas descobertas, nos sensibilizamos frente às 
generalizações, e somos mobilizados, pela metodologia da pesquisa etnográfica, a superarmos as armadilhas de explicar o que observamos pelo senso comum. Estamos acostumados a nos referir e falar de cada contexto como se fosse algo único e compartilhado da mesma forma por todos, sem considerar que os fenômenos se constituem dentro de diferentes organizações e se constroem a partir de diferentes sistemas de significados.

Olhar e ver novas possibilidades para investigar e compreender a infância e as crianças em seus diferentes contextos, respeitando suas próprias manifestações e expressões culturais permite-nos assumir a docência com maior compromisso e responsabilidade. Consideramos, portanto, a necessidade de novos olhares para com a infância e criança, remetendo-nos também a pensar em novas maneiras de narrar as suas histórias, em seus diferentes contextos, de diferentes formas e com diferentes intenções. Nessa perspectiva, revemos nosso olhar cristalizado, que enquadra e narra a história da infância e das crianças a partir de modelos homogêneos e padrões universais, para substituí-lo por um olhar investigativo e curioso, que procura, com a criança, respostas para as suas e as nossas inquietações e interroga- ções, construindo, assim, novas formas e possibilidades de ler, interpretar, produzir e narrar as diferentes historias sobre as crianças e as diferentes infâncias.

Nesse sentido, reforça-se a importância da abordagem etnográfica na investigação e na realização do estudo sobre as crianças, pois reconhecemos que a partir de seu método científico seja possível também provocar intervenções no próprio grupo pesquisado, transformando, assim, a cultura da instituição, bem como a do próprio pesquisador(a). Ambos são motivados pelo desejo de compreender as intenções e ações do outro ao tentar desvendar os acontecimentos (rituais, conflitos, eventos) em torno dos brinquedos, interpretando os sentidos neles contidos.

Lançar-se, portanto, ao desafio e à aventura de uma pesquisa etnográfica significa assumir-se um(a) educador(a) pesquisador(a), que não se submete a atingir o ponto em que parece não haver mais a necessidade do questionamento, da descoberta, de novas possibilidades e reflexões sobre a cultura do brinquedo, sobre a infância e sobre as sociedades humanas, da qual somos e fazemos todos parte. 


\section{Referências bibliográicas}

BARDIN, L. Análise de conteúdo. Lisboa: Ed. 70, 1977.

BARTHES, Roland. Como viver junto: simulações romanescas de alguns espaços cotidianos. 2. ed. São Paulo: Editora WMF Martins Fontes, 2013.

COHN, Clarice. Antropologia da criança, 2. ed. Rio de janeiro: Jorge Zahar, 2009.

DA MATA, Roberto. O ofício de etnólogo, ou como ter antropological blues. In: NUNES, Edson de Oliveira (Org.). A aventura sociológica: objetividade, paixão, improviso e método na pesquisa social. Rio de Janeiro, Zahar, 1978. p. 23-35.

DAMAZIO, Reinaldo Luiz. O que é criança. 3. ed. São Paulo: Brasiliense, 1994.

DELGADO, Ana Cristina Coll. Uma etnografia com crianças: grupos geracionais e manifestações culturais das crianças. In: REDIN, Euclides; MÜLLER, Fernanda; REDIN, Marita (Org.). Infâncias: cidades e escolas amigas das crianças. Porto Alegre: Mediação, 2007. p. 107-126.

ECKERT, Cornelia; ROCHA, Ana Luiza Carvalho da. "Etnografia: saberes e práticas". In: PINTO, Céli Regina Jardim; GUAZZELLI, César Augusto Barcellos (Org.). Ciências humanas: pesquisa e método. Porto Alegre: Editora da Universidade, 2008, p. 9-30. (Série Graduação).

FONSECA, Claudia. Quando cada caso NÃO é um caso: pesquisa etnográfica e educação. Revista Brasileira de Educação, n. 10, p. 58-78, jan./abr. 1999. Disponível em: <http://educa.fcc.org.br/pdf/rbedu/n10/n10a05.pdf>. Acesso em: 4 maio 2016.

FOOTE-WHYTE, William. Treinando a observação participante. In: GUIMARÃES, Alba. Z. Desvendando máscaras sociais. Rio de Janeiro: Francisco Alves, 1980. p. 77-86.

GOLDMAN, Marcio. Alteridade e experiência: antropologia e teoria etnográfica. Revista Etnografica, v. 10, n. 1, p. 161-173, 2006. Disponível em: <http://www.scielo.mec.pt/pdf/etn/v10n1/v10n1a08.pdf >. Acesso em: 4 maio 2016.

HISLAM, Jane. Experiências do brincar diferenciadas pelo sexo e pelas escolhas das crianças. In: MOYLES, Janete. R. et al. A excelência do brincar:a importância da brincadeira na transição entre a Educação Infantil e Anos Iniciais. Porto Alegre: Artmed, 2006. p. 50-62.

JAIME JUNIOR, Pedro. Pesquisa em organizações: por uma abordagem etnográfica. Civitas, Revista de Ciências Sociais, Porto Alegre, v. 3, n. 2, 2003. Disponível em: <http://revistaseletronicas.pucrs.br/ojs/index.php/civitas/ article/viewArticle/129>. Acesso em: 4 maio 2016.

MALINOWSKI, Bronislaw. Argonautas do Pacífico Ocidental. São Paulo: Abril Cultural; Ática, 1976. (Os Pensadores).

MARTINS FILHO, Altino José (Org.). Criança pede respeito: ação educativa na creche e pré-escola. Porto Alegre: Mediação: 2015.

MÜLLER, Fernanda; REDIN, Marita Martins. Sobre as crianças, a infância e as práticas escolares. In: REDIN, Euclides; MÜLLER, Fernanda; REDIN, Marita Martins (Org.). Infâncias: cidades e escolas amigas das crianças. Porto Alegre: Mediação, 2007. p. 11-22.

NOBRE, Domingos barros. Infância Indígena Guarani MBYA. In: VASCONCELLOS, Vera Maria Ramos; SARMENTO, Manuel Jacinto (Org.). Infância (in)visivel. Araraquara, SP: Junqueira \& Marin, 2007. p. 53-80.

OLIVEIRA, Roberto Cardoso de. O trabalho do antropólogo: olhar, ouvir, escrever. 2. ed. São Paulo: Unesp, 2000. p. 17- 36. 
SILVA, Helio R. S. A situação etnográfica: andar e ver. Horizontes Antropológicos, Porto Alegre, v. 15, n. 32, p. 171-188, jul./dez. 2009. Disponível em: <http://www.scielo.br/pdf/ha/v15n32/v15n32a08.pdf >. Acesso em: 4 maio 2016.

VASCONCELLOS, Vera Maria Ramos. Infâncias e crianças visíveis. In: VASCONCELLOS, Vera Maria Ramos; SARMENTO, Manuel Jacinto (Org.). Infância (in)visivel. Araraquara, SP: Junqueira \& Marin, 2007. p. 7-23.

WALLON, H. As origens do pensamento na criança. São Paulo: Manole, 1989.

Submissão: 22/05/2016

Aceite: $25 / 10 / 2016$ 